\title{
Social Mobility and Disability: A Neglected Relationship
}

1. Stella Chatzitheochari, Department of Sociology, University of Warwick, UK

2. Sanne Velthuis, School of Geography, Politics, and Sociology, Newcastle University, UK

3. Roxanne Connelly, Department of Sociology, University of Edinburgh, UK

\begin{abstract}
Disability theorists have long highlighted the role of institutional, social, and environmental barriers in constructing disability, emphasizing its parallels with other socially constructed axes of stratification. However, despite theoretical developments towards more sociological understandings of disability, mainstream accounts of social inequality have largely neglected disability as a social division. This research note aims to encourage social stratification and life-course research on disability by demonstrating overlooked inequalities between disabled and non-disabled young people's social mobility and early adulthood destinations. Drawing on data from the Next Steps cohort study, our visualizations shed light on stark disability differentials, highlighting the association of disability status with parental social class in influencing young people's early adulthood transitions. We proceed to outline future avenues for data collection and research that can contribute to a better understanding of the mechanisms behind these inequalities.
\end{abstract}

Keywords: disability; social class; social mobility; social stratification. 


\section{Disability in Social Stratification Research}

Recent decades have witnessed a dramatic increase in the prevalence of disability. According to the World Health Organization, 1 billion people are estimated to be disabled, corresponding to $15 \%$ of the world's population (World Health Organization, 2021). Disability rates are also on the rise in the UK, with approximately 1 in 5 citizens currently experiencing disability (Department for Work and Pensions, 2021). The association of disability with social disadvantage is well-documented: Disabled people are more likely to experience educational and occupational disadvantage, poverty, and social exclusion (Equality and Human Rights Commission, 2017). However, social stratification research has thus far shown limited empirical interest in the formation and consequences of these inequalities.

This omission seems somewhat surprising if one considers the growth of disability studies, a field of enquiry that has drawn our attention to the macro-and micro-level processes that contribute to the segregation and othering of people with impairments and long-term conditions (Barnes and Oliver, 1993). Disability scholars' recognition of disability as a contingent and socially constructed category similar to gender and race has been accompanied by a growth of empirical studies, most of which are concentrated in 'niche' fields such as special education research. Disability is rarely present in mainstream sociological accounts of inequality despite ongoing calls for the importance of social stratification and life-course research on disability inequalities (Jenkins, 1991; Powell, 2003; Shifrer and Frederick, 2019).

This lack of empirical interest is likely linked to persisting medical understandings of disability that view inequalities as caused by impairments/conditions themselves, failing to recognize the vast heterogeneity within constructed disability categories (Powell, 2003). Another barrier relates to the lack of nationally representative longitudinal datasets that provide sufficient numbers of disabled people for analysis, alongside variables that capture factors and processes likely to influence socio-economic outcomes (Velthuis and Chatzitheochari, 2021). Indeed, the majority of research on disability remains qualitative, with fewer quantitative studies that examine the effect of disability status on different educational and occupational outcomes (for example, see Chatzitheochari and Platt, 2019; Janus 2009; Shandra \& Hogan, 2009). 
Our research note aims to encourage social stratification research on disability by focusing on social mobility, a topic of fundamental importance for the study of contemporary societies. To our knowledge, ours is the first examination of this relationship, which has been consistently neglected within mainstream sociology. We demonstrate stark differences in the social origins and destinations of disabled and non-disabled young people in England and also highlight the interaction of disability status with parental social class in influencing young people's early adulthood transitions to employment and other activities. We conclude by outlining future avenues for data collection and research that can contribute to a better understanding of the mechanisms behind these inequalities.

\section{Next Steps Data}

We graphically display differences in social mobility by disability status in England, drawing on data from Next Steps, a nationally representative cohort study consisting of approximately 16,000 individuals born in 1989-1990 in England (University College London, Institute of Education and Centre for Longitudinal Studies, 2021). Next Steps is the most recent cohort study that can be used to study patterns of social mobility and transitions to adulthood of disabled adolescents in England.

Social position is measured with the 3-class version of the National Statistics Socioeconomic Classification (NS-SEC), which measures employment relations and occupational conditions (Rose and Pevalin, 2003). For parental social position, we consider the highest occupational position reported by either parent in the first wave of data collection, when cohort members were 13/14 years old. Young people's socio-economic position is measured at age 25. Because the NS-SEC is based on individuals' occupation and employment status (whether they are employed, self-employed, or an employer), NS-SEC is only available for those in employment. Disability status was measured at the same age as parental social class. Those identified as disabled had a long-standing illness, condition, or impairment affecting school attendance and/or the ability to complete homework, and/or a special educational need of any kind ${ }^{1}$. Readers are referred to Velthuis and Chatzitheochari (2021) for further details on data and measures.

\footnotetext{
${ }^{1}$ We used Wave 2 information for approximately 4 per cent of young people with missing information on disability status in Wave 1. Young people whose parents only reported "English as second language" as their special educational need were not classified as disabled in our analysis.
} 
Visualizations were produced using Stata/SE 17.0.

\section{Disability and Social Mobility in England}

The majority of young people have entered the labour market by age 25 . However, disabled young people have substantially lower rates of participation than their non-disabled peers - 64 per cent as opposed to 82 per cent (see Velthuis and Chatzitheochari, 2021).
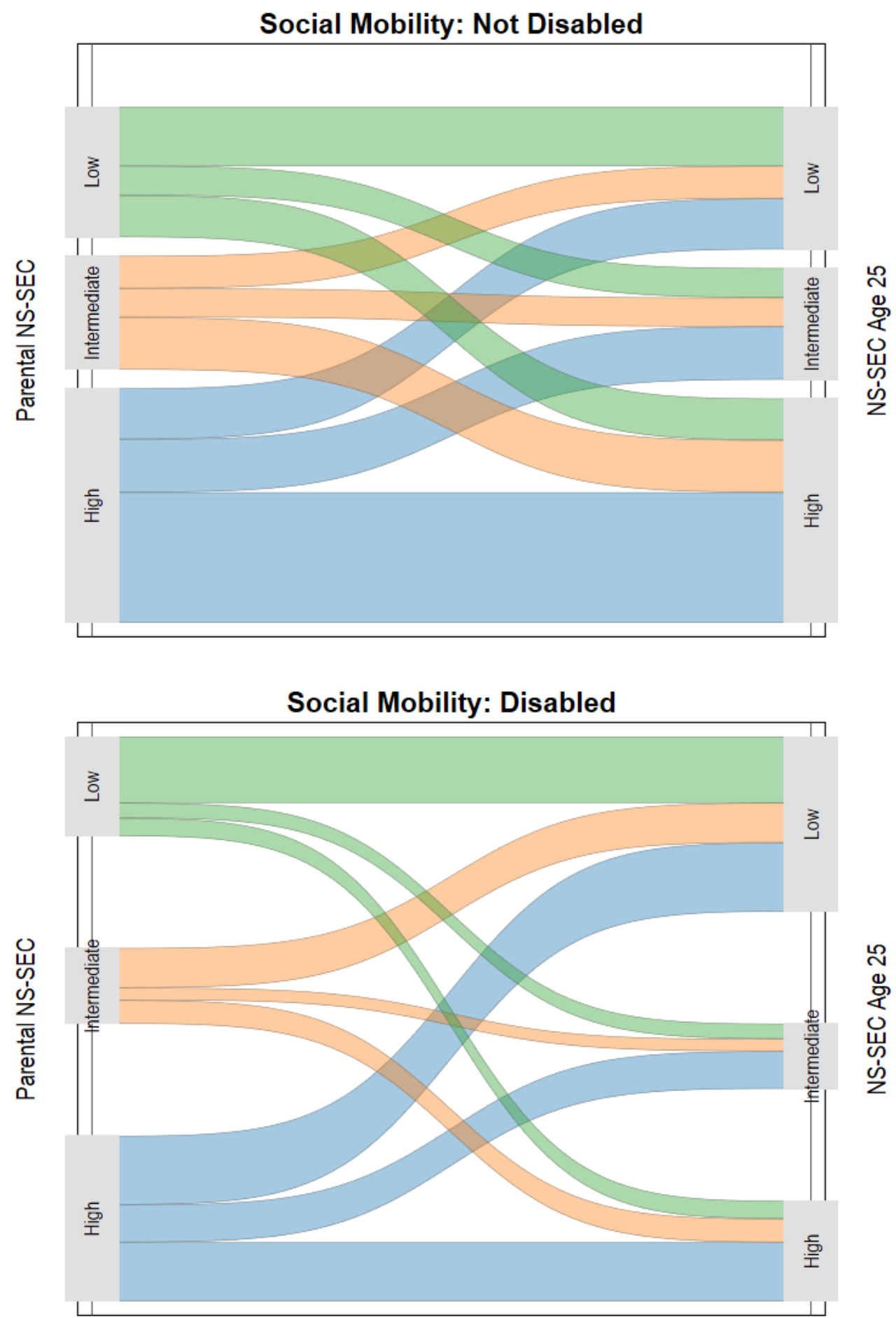
Figure 1. Social class origins and destinations at age 25, by disability status

Source: Next Steps, wave 1-8

Notes: $\mathrm{n}=5,084$ (not disabled); $\mathrm{n}=608$ (disabled). Cross sectional weights applied. Low NS-SEC includes 1) lower supervisory and technical occupations, 2) semi-routine occupations, 3) routine occupations. Intermediate NS-SEC includes 1) intermediate occupations, 2) small employers and own account workers. High NS-SEC includes 1) higher managerial, professional, and administrative occupations, 2) lower managerial, professional, and administrative occupations.

Figure 1 displays disability differences in social class origins and destinations, focusing on those who have entered the labour market at age 25 (see Tables A1 and A2 for further details). The distribution of class origins among disabled and non-disabled young people is relatively similar, as indicated by the relative sizes of the 3 parental NS-SEC categories in left-hand side of the graphs. However, there are stark differences in the rates of social class reproduction, as indicated by the pathways displayed in the two graphs. Class reproduction is far less common for disabled young people: Only 35 per cent of disabled young people from a high social position are in a similarly high social position at age 25, while 22 and 41 per cent end up in intermediate and low social positions respectively (figures available in Table A1). The situation is very different for non-disabled young people from a similar background, for whom stability is the most common outcome. Similarly, it is far less common for disabled young people from working class backgrounds to experience upward mobility compared to their non-disabled counterparts. In addition to this, the majority of disabled young people from an intermediate NS-SEC background experience downward mobility, while the opposite is the case for non-disabled young people from the same background for whom upward mobility is the most common outcome. These patterns cannot be attributed to compositional differences of the 3 social class groups (see Table A3).

We now broaden our focus to examine the entire Next Steps cohort, irrespective of labour market status. Figure 2 displays the various main activities reported by young people at age 25 by disability status and parental social class. ${ }^{2}$ This additional layer of analysis allows us to further highlight the intersection of disability with social class, an issue frequently overlooked in empirical research (Jenkins, 1991; Shifrer and Frederick, 2019). Figure 2 shows that disability inequalities in early adulthood destinations vary substantially according to social class position (see Table A4 for further details). The most pronounced

\footnotetext{
${ }^{2}$ See Velthuis \& Chatzitheochari (2021) for more information on data collection and analysis of young people's main activities in Next Steps
} 
inequalities are for employment probability: There is a 23-percentage point differential between disabled and non-disabled young people from a working-class background, as opposed to an 8-percentage point differential between those from high social class backgrounds. There are similar classed differences in reports of unemployment and sickness/disability as main activities. These patterns indicate that disability status has a disproportionate effect on young people experiencing social-economic disadvantage with respect to economic activity in early adulthood. This is an important finding that warrants further investigation.

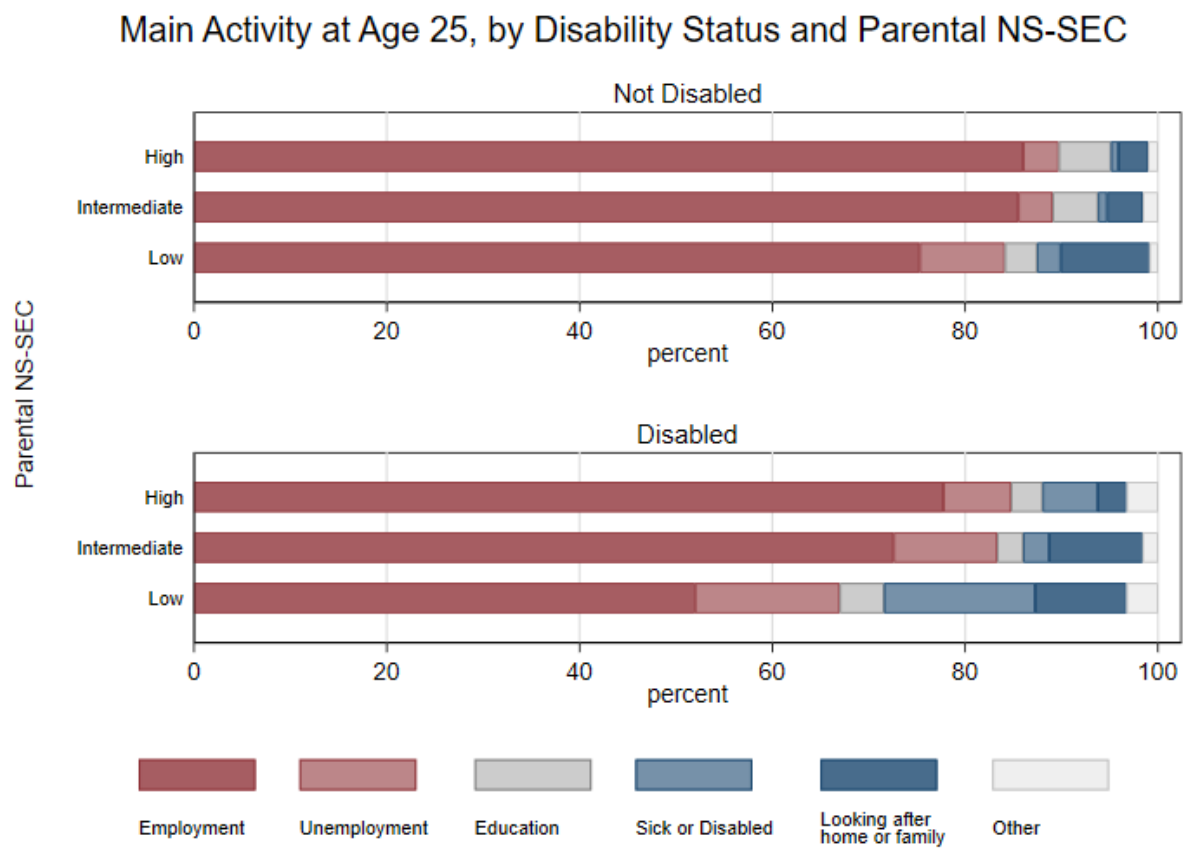

Figure 2. Main activity at age 25 , by disability status and parental social class

Source: Next Steps, wave 1-8

Notes: $\mathrm{n}=5,084$ (not disabled); $\mathrm{n}=608$ (disabled). Cross-sectional weights applied. Low NS-SEC includes 1) lower supervisory and technical occupations, 2) semi-routine occupations, 3) routine occupations. Intermediate NS-SEC includes 1) intermediate occupations, 2) small employers and own account workers. High NS-SEC includes 1) higher managerial, professional, and administrative occupations, 2) lower managerial, professional, and administrative occupations.

\section{Looking ahead: Avenues for Research on Disability Inequalities}

This note sought to highlight overlooked disability inequalities in social mobility and early adulthood destinations in an attempt to encourage social stratification research on disability. 
Although the formation of these inequalities is beyond the scope of our analysis, we conclude by outlining some future avenues for research focusing on this analytical endeavor.

A central question is the extent to which disability inequalities in educational attainment account for the social mobility patterns presented in Figure 1. Unfortunately, the majority of longitudinal studies in the UK including Next Steps provide low quality data surrounding vocational qualifications, which are particularly common for this population. It is therefore important that data collection procedures improve to better capture vocational qualifications through enhanced interview questionnaires or data linkage with the Individualized Learner Record (ILR). Such developments are necessary to better our understanding of the role of educational careers and attainment in trajectories of downward mobility of disabled young people.

Cohort studies like Next Steps are crucial for the generalized purpose of highlighting trajectories of disadvantage by disability status as well as variation by key contextual factors (Altman, 2014). However, they rarely allow analyses that differentiate by type of disability/special educational need, due to small sample sizes, which are further reduced by sample attrition (Chatzitheochari and Platt; 2019). This constitutes a barrier for understanding the mechanisms behind the inequalities documented in our note: It is possible that physical, cognitive, and socio-emotional disabilities are subject to different structural and cultural "ableisms" and forms of stigmatization (Campbell, 2009) that can in turn have different implications for early adulthood trajectories and social mobility. That is, there may be different causal paths leading to similar economic outcomes for individuals with different disabilities. Deciphering such differences can be accomplished with sampling designs that aim for large samples of people with disabilities, as well as qualitative research focusing on different broad groups of conditions/impairments.

Cohort studies can also be enhanced through consistent collection of information on duration of disability that can enable a move beyond empirical treatments that treat disability as a static state (Burchardt, 2000). Similarly, although direct measures of stigmatization and othering are difficult to collect, survey agencies may consider including separate questions linked to experiences of discrimination on grounds of one's disability. Such questions are typically collected for race and gender. We argue that disability is equally important and 
should be given more attention in multidisciplinary social surveys, considering its increasing prevalence in the UK.

Our research note highlighted the intersection of disability status with parental social class. The need to consider the ways disability interacts with other axes of inequality has been previously discussed by disability scholars (see Shifter and Frederick, 2019). Existing longitudinal surveys allow us to quantify joint effects of different axes of inequality. However, sample size restrictions do not allow us to assess whether effects like the ones underlined by our descriptive analyses are the result of classed differences in types of impairments/conditions. Use of different research designs is important to disentangle these interactions: For example, qualitative research can help clarify other mechanisms through which parental social class influences trajectories of disabled young people, e.g., through class differences in dealing with a diagnosis, accessing healthcare/school support, and encouraging positive educational and occupational expectations.

Finally, these patterns may also be a function of labour market mismatch as well as discrimination in hiring processes. These issues cannot be adequately explored through analyses of secondary data. Audit studies and vignette surveys (Bjornshagen and Ugreninov, 2021; Shamsiri-Petersen and Krogh, 2020) are therefore necessary to better understand obstacles present in the hiring of disabled young people from different class backgrounds.

\section{Bibliography}

Altman, B. 2014 Definitions, Concepts, and Measures of Disability, Annals of Epidemiology, 24(1): 2-7

Barnes, C., and Oliver, M. 1993 Disability: A Sociological Phenomenon Ignored by Sociologists. Leeds, England: Centre for Disability

Studies, University of Leeds.

Bjornshagen, V.\& Ugreninov, E. 2021 Disability Disadvantage: Experimental Evidence of Hiring Discrimination against Wheelchair Users, European Sociological Review, 37(5): 818833

Burchardt, T. 2000 The Dynamics of Being Disabled. Case Paper 36. London School of Economics. 
Campbell, F.K. 2009 Contours of Ableism: Territories, Objects, Disability and Desire. Palgrave Macmillan.

Chatzitheochari, S., and Platt, L. 2019 'Disability Differentials in Educational Attainment in England: Primary and Secondary Effects', British Journal of Sociology, 70(2):502-525

Department of Work and Pensions 2021 Family Resources Survey: Financial Year 2019 to 2020. London: Department of Work and Pensions. Accessed 4 February 2022.

[https://www.gov.uk/government/statistics/family-resources-survey-financial-year-2019-to2020/family-resources-survey-financial-year-2019-to-2020]

Equality and Human Rights Commission 2017 Being Disabled: A Journey Less Equal. London: Equality and Human Rights Commission

Janus, A.L. 2009 'Disability and the Transition to Adulthood', Social Forces, 88(1):99-120

Jenkins, R. 1991 'Disability and Social Stratification', British Journal of Sociology, 42(4): 557-80.

Powell, J. 2003 'Constructing Disability and Social Inequality Early in the Life Course: The Case of Special Education in Germany and the United States', Disability Studies Quarterly, 23(2): 57-75.

Rose, D, and Pevalin, D. 2003 A Researcher's Guide to the National Statistics Socioeconomic Classification, London: Sage.

Shamsiri-Petersen, and Krogh, C. 2020 Disability Disqualifies: A Vignette Experiment of Danish Employers Intentions to Hire Applicants with Physical Disabilities, Scandinavian Journal of Disability Research, 22(1): 198-209

Shandra, C.L. and Hogan, D. 2009 'The Educational Attainment Process Among Adolescents with Disabilities and Children of Parents with Disabilities', International Journal of Disability, Development and Education, 56(4):363-379

Shifrer, D. \& Frederick, A. 2019 'Disability at the Intersections', Sociology Compass 13(10): e12733

University College London, Institute of Education, Centre for Longitudinal Studies 2021 Next Steps: Sweeps 1-8, 2004-2016 [data collection]. 15th Edition. UK Data Service.

Velthuis, S. \& Chatzitheochari, S. 2021 'Adolescent Disability, Post-16 Destinations, and Educational Attainment: Initial Evidence from Next Steps', SocArxiv

World Health Organization 2021 Fact Sheet: Disability and Health. World Health Organization. Accessed 4 February 2022 [https://www.who.int/news-room/factsheets/detail/disability-and-health] 


\section{Appendix}

Table A1: Social mobility measured at age 25, by disability status

\begin{tabular}{lcccc}
\hline & \multicolumn{4}{c}{ NS-SEC at age 25 } \\
\cline { 2 - 5 } Parental NS-SEC at age 13/14 & High & Intermediate & Low & Total \\
\hline High $(\mathrm{n}=296)$ & 35.5 & 22.7 & 41.7 & 100 \\
Intermediate $(\mathrm{n}=135)$ & 30.9 & 16.4 & 52.8 & 100 \\
Low $(\mathrm{n}=177)$ & 18.0 & 15.4 & 66.6 & 100 \\
All $(\mathrm{n}=608)$ & 28.4 & 18.7 & 52.9 & 100 \\
\hline & \multicolumn{4}{c}{ Not disabled } \\
Parental NS-SEC at age 13/14 & High & Intermediate & Low & Total \\
\hline High $(\mathrm{n}=2,490)$ & 55.6 & 22.7 & 21.7 & 100 \\
Intermediate $(\mathrm{n}=1,209)$ & 45.9 & 25.5 & 28.6 & 100 \\
Low $(\mathrm{n}=1,385)$ & 32.0 & 22.6 & 45.4 & 100 \\
All $(\mathrm{n}=5,084)$ & 46.3 & 23.3 & 30.4 & 100 \\
\hline
\end{tabular}

Source: Next Steps, wave 1-8.

Table A2: Patterns of social mobility at age 25 by

disability status

\begin{tabular}{lccc}
\hline & $\begin{array}{c}\text { Not } \\
(\mathrm{n}=608)\end{array}$ & $\begin{array}{c}\text { disabled } \\
(\mathrm{n}=5,084)\end{array}$ & $\begin{array}{c}\text { All } \\
(\mathrm{n}=5,692)\end{array}$ \\
\hline Downward mobility & 39.4 & 27.5 & 29.2 \\
Stability & 42.0 & 45.4 & 44.9 \\
Upward mobility & 18.6 & 27.2 & 25.9 \\
Total & 100 & 100 & 100 \\
\hline
\end{tabular}

Source: Next Steps, wave 1-8.

Table A3: Composition of NS-SEC groups at age 25, by disability status

\begin{tabular}{lccc}
\hline High NS-SEC & $\begin{array}{c}\text { Disabled } \\
(\mathrm{n}=372)\end{array}$ & $\begin{array}{c}\text { Not disabled } \\
(\mathrm{n}=2,894)\end{array}$ & $\begin{array}{c}\text { All } \\
(\mathrm{n}=3,266)\end{array}$ \\
\hline $\begin{array}{l}\text { Higher managerial, professional and } \\
\text { administrative occupations }\end{array}$ & 27.5 & 32.5 & 31.8 \\
$\begin{array}{l}\text { Lower managerial, professional and } \\
\text { administrative occupations }\end{array}$ & 72.5 & 67.5 & 68.2 \\
Total & 100 & 100 & 100 \\
\hline & $\begin{array}{c}\text { Disabled } \\
(\mathrm{n}=186)\end{array}$ & $\begin{array}{c}\text { Not disabled } \\
(\mathrm{n}=1,407)\end{array}$ & $\begin{array}{c}\mathrm{n}=1,593) \\
\text { Intermediate NS-SEC }\end{array}$ \\
\hline $\begin{array}{l}\text { Intermediate occupations } \\
\text { Small employers and own account workers }\end{array}$ & 48.2 & 54.3 & 53.9 \\
Total & 100 & 45.7 & 46.1 \\
& & 100 & 100
\end{tabular}




\begin{tabular}{lccc}
\hline Low NS-SEC & $\begin{array}{c}\text { Disabled } \\
(\mathrm{n}=308)\end{array}$ & $\begin{array}{c}\text { Not disabled } \\
(\mathrm{n}=1,787)\end{array}$ & $\begin{array}{c}\text { All } \\
(\mathrm{n}=2,095)\end{array}$ \\
\hline Lower supervisory and technical occupations & 27.6 & 30.4 & 29.8 \\
Semi-routine occupations & 39.0 & 43.5 & 42.5 \\
Routine occupations & 33.4 & 26.1 & 27.7 \\
Total & 100 & 100 & 100 \\
\hline
\end{tabular}

Source: Next Steps, waves 1-8. 
Table A4: Disability differentials in main activities at age 25, by parental NS-SEC at age 13/14

\begin{tabular}{|c|c|c|c|c|c|c|c|c|c|}
\hline & $\begin{array}{c}\text { Disabled } \\
(\mathrm{n}=367)\end{array}$ & $\begin{array}{c}\text { (percentage } \\
\text { activity) } \\
\text { Not } \\
\text { disabled } \\
(\mathrm{n}=2,887) \\
\end{array}$ & each main & $\begin{array}{l}\text { Disabled } \\
(\mathrm{n}=185)\end{array}$ & $\begin{array}{l}\text { iate NS-SEC } \\
\text { each main acti }\end{array}$ & $\begin{array}{l}\text { rcentage in } \\
\text { ty) }\end{array}$ & $\begin{array}{l}\text { Disabled } \\
(\mathrm{n}=305)\end{array}$ & $\begin{array}{c}\text { SEC (percenta } \\
\text { main activity) }\end{array}$ & e in each \\
\hline Employment & 78.0 & 85.9 & -7.9 & 72.8 & 85.5 & -12.7 & 52 & 75.4 & -23.4 \\
\hline Unemployment & 7.1 & 3.7 & 3.4 & 10.6 & 3.6 & 7.0 & 15.1 & 8.8 & 6.3 \\
\hline Education & 3.3 & 5.4 & -2.1 & 2.6 & 4.7 & -2.1 & 4.6 & 3.4 & 1.2 \\
\hline $\begin{array}{l}\text { Sick or disabled } \\
\text { Looking after }\end{array}$ & 5.6 & 0.8 & 4.8 & 2.8 & 0.9 & 1.9 & 15.6 & 2.4 & 13.2 \\
\hline home or family & 2.9 & 3.1 & -0.2 & 9.6 & 3.7 & 5.9 & 9.4 & 9.2 & 0.2 \\
\hline Other & 3.2 & 1.0 & 2.2 & 1.6 & 1.6 & 0 & 3.4 & 0.9 & 2.5 \\
\hline Total & 100 & 100 & & 100 & 100 & & 100 & 100 & \\
\hline
\end{tabular}

Source: Next Steps, wave 1-8 